\title{
A New Model and Its Practice in Language Learning Strategy Training*
}

\author{
Li Gao \\ Foreign Language School, Southwest Petroleum University, Xindu, Chengdu, Sichuan, China \\ Yun $\mathrm{He}$ \\ Freshmen Education Department, Yangtze University, Jingzhou, Hubei, China \\ Jie Zeng \\ Foreign Language School, Southwest Petroleum University, Xindu, Chengdu, Sichuan, China
}

\begin{abstract}
Learning will be facilitated if students are explicitly trained to become more aware of and proficient in the use of a broad range of strategies that can be utilized in the language learning process. A new learning strategy training model, TCLTSP Model, is designed, focusing on the understanding of learners themselves, understanding the target, and understanding learning strategies, aiming at taking conscious control of learning process. Two examples - learner preference and vocabulary learning strategy training class are demonstrated to illustrate how to practice this model in authentic classes.
\end{abstract}

Index Terms-learning strategy training, TCLTSP Model, learner preference, vocabulary learning strategy, teaching practice

\section{INTRODUCTION}

As the research of language learning and teaching enters a new century, learning strategy training, which is an important way for helping students become more autonomous and self-regulated, has become one of the prominent themes (O'Malley \& Chamot 1990; Oxford 1990; Wenden 1991; Cohen 2000). Cohen (2000) states that "foreign language program administrators can contribute to this effort by offering strategy training to students as part of the foreign language curriculum". (p.67) However, strategy training does not mean simply instructing the same strategies to be regularly adopted and used by language learners; it should be conducted based on the analysis of individual learner's factors and under the guidance of an appropriate model. Therefore, after analyzing five strategy-training models, this article discusses the design and authentic practice of a new model - TCLTSP Model for explicit foreign language learning strategy training. This article aims at demonstrating how strategy training program based on TCLTSP model for freshmen is carried out in Southwest Petroleum University in China, hoping to give teachers implication on foreign language strategy instruction in authentic classes.

\section{Review of Five StRategy Training Models}

Learning strategy models are helpful in illustrating the ways in which research findings can be converted into classroom practice. Among instructional models designed in the researches of strategy training, the following five models are most famous: The Strategic Teaching Model, developed by Jones et al. (1987) (cited from O'Malley \& Chamot(1990)); The Cognitive Academic Language Learning Approach (CALLA) model, designed by O'Malley \& Chamot (1990); The CRAPEL Model (the Centre de Recherches et d' Applications Pedagogiques en Langues) (Oxford, 1990, P.217); The Flower Model(Leni Dam's approach to primary school language instruction in Denmark) (Oxford, 1990); Oxford's model (1990).

All of these five models boast their particular features which set them apart from their competitors - investigating strategies adopted by learners and developing learners' motivation in The Strategic Teaching Model; bringing content subjects, academic language skills and learning strategies together in CALLA Model; assigning a "helper" in CRAPEL Model; focusing on the interdependence of Objectives, Activities, Outcomes, Evaluation, Pupils' Contributions, and Materials in Flower Model; making sure the learners aware of the rationale for strategy use in Oxford's model. These models all place more weight on discussions about the use and value of strategies, encourage conscious and purposeful strategy use and transfer, and allow students to monitor their performance and evaluate the effectiveness of the strategies they are using.

\section{TCLTSP MODEL}

${ }^{*}$ SCWYH16-07 
TCLTSP Model is designed in the practices of learning strategy training for Chinese learners who study English as a foreign language from the year of 2008 to 2015. Compared with the above five models which focus on instructing language learning strategies, TCLTSP Model owns five points of difference: (1) Learning strategy use is closely combined with learners' factors. The above five models require instructors understand learners' present language strategy use before training, while TCLTSP model emphasizes instructors understand learners' factors before training, such as learners' preference, self-learning goals and monition, etc. (2) Learning strategy use is closely combined with the feature of target language. The above models do not require learners to understand target language, while this model argues that foreign language learners may have misunderstanding on the features of target language, which influence learners' strategy use, therefore learners need to understand the features of target language in training, such as understanding the nature and feature of listening, speaking, reading, writing and vocabulary learning, etc. (3) "Classroom activities" are applied in above models to help learners understand and learn strategy, and " task experience" is applied in TCLTSP model. "Classroom activities" only have language learning purposes, while "tasks" own non-language learning purpose, which is more communicative, open and interactive, such as the task "learners listen to a piece of absolute music, and write down pictures in their mind brought by this music, and then reflect why different learner has different picture." Here the purpose of this task is not to improve learners' language proficiency, but to make them feel the importance of prior knowledge. (4) "Reflection" is not mentioned in the above five models, while TCLTSP model emphasizes reflecting task experience. Learners are required to think how to carry out tasks correctly and effectively, recall the task experience and reflect their strategy use and difficulties they met in task-doing. Especially, "reflection" is integrated into training content, learners are required not only to reflect "reflection strategy", but also to experience "how to use reflection strategy". (5) A "helper" is assigned in CRAPEL Model, and learners groups are arranged in other existing models; while TCLTSP model has one lecturer and several assistant teachers, and these assistants are assigned in each learners' group, which strengthen the cooperation among teachers through co-teaching, and that of teachers-learners through group activities, and teachers' monitoring, guiding and helping.

The TCLTSP Model is theoretically based on self-regulated learning and experiential learning. Self-regulated learning (SRL) is learning that is guided by metacognition (thinking about one's thinking), strategic action (planning, monitoring, and evaluating personal progress against a standard), and motivation to learn (Zimmerman, 1990). "Self-regulated" describes a process of taking control of and evaluating one's own learning and behavior. It involves three phases - forethought phase (learners analyze tasks and enhance self-motivation beliefs), performance phase (learners adopt strategies to make self-control and self-observation) and self-reflection phase (learners make self-judgment and self-reaction). In self-regulated process, learners understand why, how, when, where and how to learn. TCLTSP Model is based on self-regulated learning, for the model emphasizes recognizing and reflecting learners' effective strategy use, with the aim of taking control language learning process. Based on earlier work by John Dewey and Kurt Levin, American education theorist David A. Kolb believes "learning is the process whereby knowledge is created through the transformation of experience" (1984, p.38), in which four stages are involved - concrete experience (learners actively experience activities), reflective observation (learners consciously reflect back on that experience), abstract conceptualization (learners conceptualize what is observed), active experimentation (learners try to test what is conceptualized and plan for a forthcoming experience). TCLTSP Model is also based on experiential learning, for the model emphasizes acquiring new knowledge, skills and attitude in task practice and reflective practice, through experience, perception and cognition.

LTSTC Model has six phases and six components. The six phases are not carried out step by step, but integrated into different components, and each component contains two or three phases.

These six phases are:

Phase 1- experience, learners are encouraged to do one or several tasks to raise their awareness in knowing their learner factors and language proficiency at present level, in recognizing features of learner factors and learning process, and in learning to effectively use strategies instructed by teacher in task experience phase.

Phase 2 - discussion, learners are asked to discuss how they finish the task, what difficulties they have when they experience the task, and how they use strategies when they are doing tasks with the aid of tutors. After Phase 1, learners must have perception on their task experience respectively; however, what they observed or felt is restricted in individual perception. Therefore, Discussion Phase can help learners fully and thoroughly understand what and how they did while they are experiencing tasks by sharing thoughts and ideas with group members.

Phase 3 - expansion, learners are instructed: (a) the definition, categories and features of learner factors and learning processes (namely, listening, reading, writing, speaking, and vocabulary study processes) explicitly; (b) important language learning strategies and how to use these strategies effectively. As to one language skill, one or two important strategies may be instructed in depth; the other strategies are introduced in simpler way.

Phase 4- re-experience, learners are encouraged to apply more strategies in new tasks. In the process, they are required to think over why and how to use these new strategies by themselves and asked to transfer new strategies through different tasks. Eventually, after repeatedly selecting and adjusting strategies they used in new tasks, learners find self- adaptive language learning strategies.

Phase 5- reflection, learners make reflection on their experience processes and re-experience processes. In experience process, learners reflect their learning habits, their comfort zones in strategy use, their questions and 
difficulties on language learning process. In re-experience process, learners reflect how they select and adjust strategies based on the characteristics of themselves, and eventually they conceptualize their self-adaptive language learning strategy repertoire.

Phase 6 - evaluation, learners are helped to evaluate the changes they have in recognition on their learner factors, the target language and strategies adaptive to themselves, and the changes in attitude toward foreign language learning, with the help of learner portfolio. And learners also evaluate whether they can use their new self-adaptive learning strategy repertoire effectively and automatically.

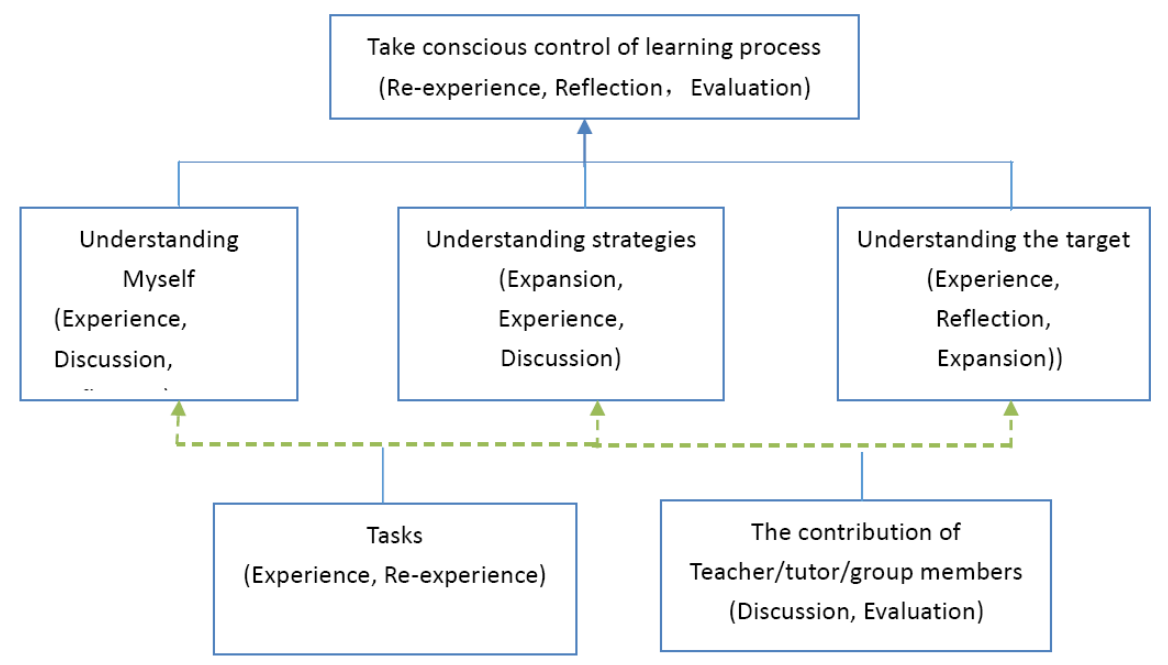

Figure 1: TCLTSP Model

The components in TCLTSP Model are implemented based on task experience. In the model, "T" stands for "Tasks experiencing", "C" for "Contribution of teacher/ tutors/group members", "L" for "Learners' self-understanding", "T" for "understanding of Target", "S" for "understanding learning Strategies", and "P" for "taking conscious control of learning Process".

"Tasks experiencing" and "Contribution of teacher/ tutors/group members" are supporting components of the model. "Tasks experiencing" contains two phases - experience and re-experience phases. Learners finish different kinds of tasks designed by teacher, and at the same time, they perceive their task doing and language learning processes. "Contribution of teacher/ tutors/group members" also contains two phases - discussion and evaluation; it refers that teacher and tutors provide learning materials and tasks to learners, discuss with learners in groups, give advices to learners when asked, and help learners use portfolio to make reflection and evaluation, meanwhile tutors need to observe and monitor learners in and after classes.

"Learners' self-understanding", "understanding of Target", and "understanding learning Strategies" are core components of the model, which also are distinguish elements of TCLTSP Model. Cohen \& Weaver (2006) put forward that strategies can be classified by skill area, which includes the receptive skills of listening and reading and the productive skills of speaking and writing and skill-related strategies that cut across all four skill areas, such as vocabulary strategies and intercultural communication strategies. Furthermore, Oxford (2001) maintained that language learner strategies need to be viewed through the perspective of some learner factors. Therefore, both the target language (language skills and cultural awareness) and learner factors are covered in the three core components.

In "Learners' self-understanding" component, by experiencing tasks, making discussion and reflection, learners get knowledge on their present learner preferences, roles in a group and identities in intercultural communication, the features of their memory, their goals, motivation, determination, EQ/IQ/AQ, and their behaviors as a foreign language listener/speaker/reader/writer/vocabulary learner, aiming at understanding their cognition schema intellectually and non-intellectually.

By experiencing tasks, making reflection and getting expansion from teachers, learners "understand target" definition, classification and features of learner preference, group working, foreign language learning goals, learners' motivation, determination, EQ/IQ/AQ; and the essence of target language learning (listening, reading, speaking, writing, vocabulary study and intercultural communication).

By teacher's expansion, learner's experience and discussion, teacher introduces foreign language learning strategies and how to use these strategies effectively to leaners and let them use these strategies in the component of "understanding learning Strategies". In teacher's expansion phase, learners have a thorough understanding on language learning strategies. In experience phase, learners try to use these strategies in tasks, and in discussion phase, they discuss how they use these strategies and whether they can use them effectively.

"Taking conscious control of learning Process" is the target component of the model; it contains three phases re-experience, reflection and evaluation. Learners repeated experience different tasks and reflect in and on their 
experiencing processes, simultaneously they choose the strategies which are best adaptive to themselves. And finally they evaluate whether they can control their language learning process. In this component, reflection is very important, for learners need to gain their self-adaptive learning strategy repertoire through their self-reflecting.

TABLE 1:

FEATURES OF TCLTSP MODEL

\begin{tabular}{|c|c|c|c|}
\hline Self-understanding & $\begin{array}{l}\text { Target- } \\
\text { understanding }\end{array}$ & Strategies instruction & \\
\hline My learner preference & Learner preference & $\begin{array}{l}\text { Explore my comfort zone in learner } \\
\text { preference; } \\
\text { Recognize individual difference in learner } \\
\text { preference }\end{array}$ & \multirow[t]{4}{*}{$\begin{array}{l}\text { Learner } \\
\text { Factors } \\
\text { (Experience } \\
\text { "reflection") }\end{array}$} \\
\hline $\begin{array}{l}\text { My goal } \\
\text { My motivation } \\
\text { My determination } \\
\text { My Adversity Quotient }\end{array}$ & $\begin{array}{l}\text { Goal } \\
\text { Motivation } \\
\text { Determination } \\
\text { Adversity quotient }\end{array}$ & $\begin{array}{l}\text { Set my goals; } \\
\text { Make use of motivation; } \\
\text { Enhance my determination; } \\
\text { Enhance my AQ }\end{array}$ & \\
\hline $\begin{array}{l}\text { Myself as a team } \\
\text { member }\end{array}$ & Roles in a team & Position myself in a team & \\
\hline $\begin{array}{l}\text { My memory } \\
\text { characteristics }\end{array}$ & Memory curve & Memory strategies & \\
\hline $\begin{array}{l}\text { Myself in vocabulary } \\
\text { study }\end{array}$ & $\begin{array}{l}\text { Vocabulary study } \\
\text { process }\end{array}$ & Vocabulary study strategies & \multirow{6}{*}{$\begin{array}{l}\text { Target } \\
\text { Language } \\
\text { (Experience } \\
\text { "reflection") }\end{array}$} \\
\hline Myself as a listener & Listening process & Listening strategies & \\
\hline Myself as a speaker & Speaking process & Speaking strategies & \\
\hline Myself as a reader & Reading process & Reading strategies & \\
\hline Myself as a writer & Writing process & Writing strategies & \\
\hline $\begin{array}{l}\text { My intercultural } \\
\text { sensitivity }\end{array}$ & $\begin{array}{l}\text { Hidden core of } \\
\text { culture }\end{array}$ & $\begin{array}{l}\text { Strategies to develop intercultural } \\
\text { competence }\end{array}$ & \\
\hline My reflective practice & Reflection & Reflective strategies & $\begin{array}{l}\text { Higher order thinking } \\
\text { (Reflect "reflection") }\end{array}$ \\
\hline
\end{tabular}

In summary, TCLTSP Model integrates learner factors and target language study into self-understanding and target-understanding (see Table 1). By analyzing task experiences, learners understand their present learner factors and their present behavior in target language learning, finding their weaknesses and strengths in these aspects. By reflecting their task experience and getting instruction from teacher, learners can understand deeply on learner factors and catch language study essence so that they can try to stretch their comfort zones and mend their fences after repeated practice, and form correct language learning belief. What's more, teacher's instruction of language learning strategies is based on learners' full understanding of their learner factors and target language. Only by doing so, can they form learning strategy repertoire which are best adaptive to themselves.

TABLE 2

THE CURRICULUM OF TCLTSP MODEL STRATEGY TRAINING

\begin{tabular}{|l|l|}
\hline Unit 1Learner Preference & \multirow{2}{*}{$\begin{array}{l}\text { Experience } \\
\text { "Reflection" }\end{array}$} \\
\hline Unit 2 Goals, Motivation and Perseverance & \\
\hline Unit 8 Positioning in a Grouping & \\
\hline Unit 3 Memory (and Vocabulary) & \\
\hline Unit 3 (Memory and) Vocabulary & \\
\hline Unit 4 Listening & Reflect "Reflection" \\
\hline Unit 5 Speaking & \\
\hline Unit 6 Reading & \\
\hline Unit 7 Writing &
\end{tabular}

\section{Application OF TCLTSP MOdEL IN STRATEGy TRAining}

A group of teachers and graduate students in SWPU set out a language learning strategy training program, aiming to orientate freshmen how to learn a foreign language effectively. As for "learner factors", learners are first aided to identify their learner preferences, goals, motivation, determination, EQ/IQ/AQ, their membership in a team, and their memory characteristics, and then they are given a thorough, systematical and detailed instruction to concept and categories of "learner preference, goals, motivation, determination, EQ/IQ/AQ, roles in a team and memory curve", and finally learners are aided to master strategies - "explore my comfort zone in learner preference; recognize individual difference in learner preference; set my goals; make use of motivation; enhance my determination; enhance my AQ; position myself in a team; memory strategies. As for "target language", learners are first aided to understand their present performance as language learner - "myself in vocabulary study; myself as a listener; myself as a speaker; myself as a reader; myself as a writer; my intercultural sensitivity", and then they are given a thorough, systematical and detailed instruction to definition, categories and function of "vocabulary study process, listening process, speaking 
process, reading process, writing process, and hidden core of culture", and finally learners are helped to mater vocabulary study strategies, listening/speaking/reading/ writing strategies, and strategies to develop intercultural competence. As for "higher order thinking", learners first recall their reflective practice in language learning, and they get full comprehension on definition, categories and function of "reflection" by teacher instruction, and finally learners are helped to master reflective strategies. (See Table 1) The curriculum of TCLTSP Model Strategy Training for foreign language freshmen can be seen in table 2 .

\section{A. Practice of TCLTSP Model in Learner Preference}

Lecture on "learner preference" is a typical example of how this strategy training program develops learners' strategies on learner factors, which casts us lights on non-intelligence factors training.

Time arranged: 135 minutes

Teaching method: team teaching (professor instructing and assistants participating in group discussion, monitoring and observing learners)

Teaching objective: (1) Understanding learner preference; (2) Identifying your own learner preference; (3) Consciously taking control of the learning process.

Warm-up Activities: Teacher raises questions among students: "Have you ever thought about what types of lessons you prefer most in school? Do you like reading from the text on your own? Would you rather listen to others reading from the book? Do you like working with your classmates or would you rather complete an assignment by yourself?" The aim of this questions-raising activity is to let students know their preferences tell the tendencies they will learn a language, especially when they facing a multitude of learning strategies. Therefore, to be an effective learner, they might as well know themselves first, and select learning strategies in accordance with their own learner preferences.

\section{Understanding Yourself as a Learner}

Students are asked to do a survey task, and then draw a picture with the aid of assistant teachers. Students are told to count how many Vs, As, and Ks they circled, to divide each number by 7 and multiply by 15, to find the point on their corresponding line (A stands for Aural; V visual; $\mathrm{K}$ kinesthetic), and then to connect three points and get a triangle (see figure 2). The survey is as following (Zeng, 2011):

1. You are driving to your friend's house, but you don't know his address. Would you like him to:

V. draw you a map? A. tell you directions? K. collect you in their car?

2. You are going to cook a dessert as a special treat for your family. Do you:

K. cook something usual? A. ask for advice from others?

V. look for ideas from a cookbook's pictures and instructions?

3. When you got your first mobile phone, how did you learn to use it best? by:

$V$. visual clues-pictures, diagrams, charts and written instructions?

A. listening to your friends' experience? K. using it?

4. You are about to learn how to use a new program on a computer. Would you:

K. ask a friend to show you? A. telephone a friend and ask questions about it?

$V$. read the handbook which comes with the program?

5. You are not sure whether a word should be spelled "dependent" or "dependant". Do you:

V. imagine it in mind and choose the best way it looks? A. sound it out?

$K$. write both versions down or look up the dictionary?

6. Which of these games do you prefer?

V. Pictionary? A. Whisper game? K. Charades?

7. Do you prefer a lecturer/teacher who likes to use?

$V$. flow diagrams, charts, slides (PPT)? A. discussion, guest speakers?

K. field trips, labs, practical sessions?
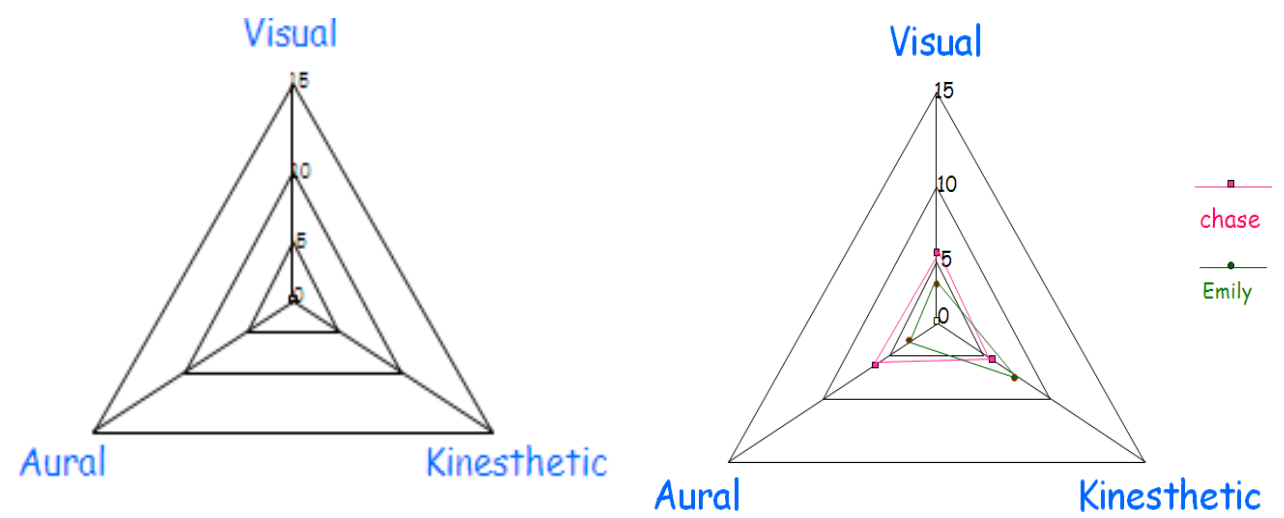

Figure 2: Sensory preferences, cited from Zeng (2011) 
Teacher instructs what visual/aural/kinesthetic learners are by exemplifying: Visual learners "prefer using pictures, colors, and maps to organize information; see pictures, numbers, or words in his/her mind; understand /remember things better if he/she writes them down."Aural learners "remember things better if he/she discusses them with someone; like to listen to music when he/she studies; when turning on the TV, he/she listens to the sound more than watches the screen."Kinesthetic learners "often use more body languages to communicate; like thinking out issues, ideas and problems by moving around; enjoy learning by doing."

\section{Learner Preferences and Foreign Language Learning}

Teacher gives advices to learners of different sensory preferences, for example: visual learners "rely more on the scene of sight and learn best through visual means (books, video, charts, pictures)"; aural learners "prefer listening and speaking activities (discussions, role-plays, lectures)"; kinesthetic learners "benefit from doing projects, working with objects, and moving around the room (games, conducting experiments)." Meanwhile, the weaknesses of each sensory preferences learners in language study are also instructed, for example: visual learners "are poor in speaking; have trouble in following spoken directions; not retain what they hear for very long"; aural learners "distracted by noise; write smoothly and not always readable; are poor in reading comprehension"; kinesthetic learners "are poor spellers; are not good readers; don't hear things well"'.

Students discuss in groups, identify their sensory preferences, and analyze their learning features related to these preferences with the help of assistant teachers. For example, one student report "I prefer aural and kinesthetic learning, for I like to play my pen and hair when studying and I like listening to something when studying and when getting bed. I think listening can help me focus my attention, so I like listening better. But still, I also like to imagine picture in my mind when studying." Another student says" I prefer visual learning, but I know listening is very important."

\section{Understanding Learner Preferences}

Teacher instructs other learner preferences to students: in personality types, there are extroverted/introverted learners and open/ closure-oriented learners; in cognitive styles, there are global and analytic learners. Features for each learner preference are also instructed, for example: extroverted leaners "are Energized by the outside world; are active, interaction-oriented, and outgoing; have broad interests; tend to reflect later"; introverted learners "are Energized by the inner world; prefer concentration; focus on thoughts and concepts; have fewer interests, but deeper ones; like to be reflective"; open learners "are Information gatherer; like to take in a lot of information and experience before making a decision, have a high tolerance for ambiguity; tend to be flexible and open to change; find deadlines as artificial and arbitrary"; closure-oriented learners " are decision makers; action takers; make and follow tips; want quick closure and control; have a low tolerance for ambiguity, find deadlines helpful"; global learners "enjoy getting the main idea and are comfortable communicating even if they do not know all the words or concepts"; analytic learners "need specific examples to understand fully; pay attention to specific factors or information; are good at catching new phrases or words".

\section{Understanding Yourself as a Learner}

Students are asked to do a survey and they are told to circle their immediate responses to six items, multiply each score by two, find the point on their corresponding line (E stands for extroverted; I introverted; C closure; O open; G global; A analytic), connect all points with adjoining points, and get a hexagon (see figure 3). The survey is as following (Zeng, 2011):

$0=$ never $1=$ rarely $2=$ sometimes $3=$ often $4=$ usually $5=$ always

E. I meet new people easily by jumping into the conversation. $\quad 012345$

I. When I am in a large group, I tend to keep silent and listen. $\quad 012345$

C. I like to be certain about what things mean in English. $\quad 012345$

O.I don't feel the need to come to rapid conclusions about a topic. 012345

G. When I tell an old story, I tend to forget lots of specific details. 012345

A. I need very specific examples in order to understand fully. $\quad 012345$

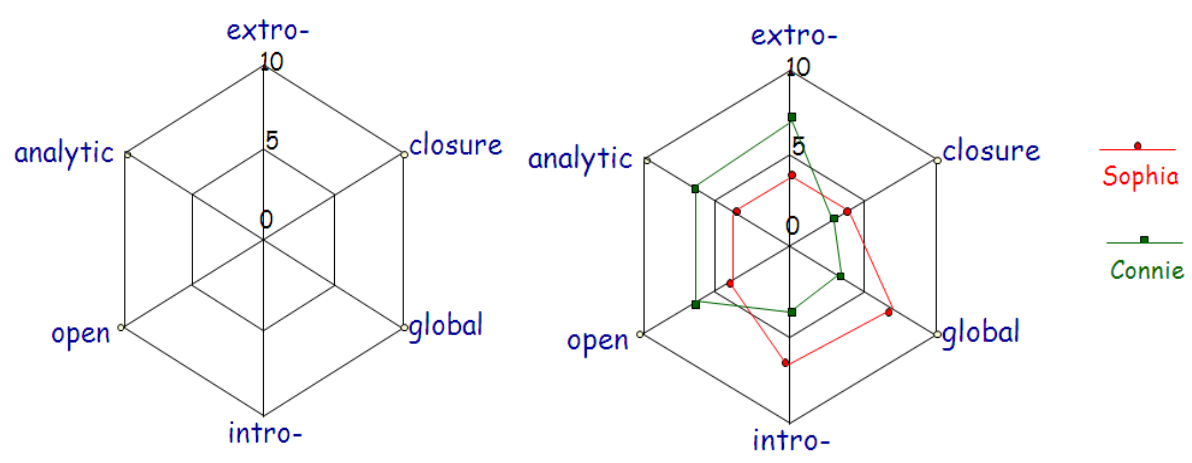

Figure 3: Personality and Cognitive Preferences, cited from Zeng (2011)

\section{Learner Preferences and Foreign Language Learning}


Students discuss in groups their learning features related to their learner preferences. For example, one student reports "sometimes I'm extroverted and sometimes I'm introverted, I like to chat and discuss with others, and I also like to do my homework alone. I'm more closure-oriented learner for I always make plan. I'm more global learner for I always get general ideas, even when I can't understand others' conversations, therefore I don't focus on details and I feel I'm lazy in thinking. Now I recognize this weak point, and I will force myself focus more on details in my learning processes." Another student reports "I'm a more extroverted girl, and I like group activities and present my opinion to others, but sometimes I still do my business alone. I'm very interested in western culture, so I like English, but my poor grammar gets me stuck. I think this is because I'm more global learner and do not focus on details. So I will change this weak point step by step. I'm more open learner, and I like learn in free atmosphere, so I always feel my mind is oppressed and want get out of the classroom to breathe fresh air when I attend class for longer time."

Teacher explains to students that everyone is unique and individual differences are existed in our study, what more, there is no good or bad learner preference and there are strong and weak points for each preference. Therefore, what students need to do is analyzing themselves and identifying their learner preferences, so that they can adjust their preference in given context for better foreign language study.

\section{Assignment}

Two tasks are assigned to students in this class. One is investigating task. Students are asked to observe or interview one of their teachers, analyze and exemplify his/her learner preferences and teaching characteristics. And then students need to compare this teacher with themselves and find weather their preference differences bring conflicts to their learning.

Another is reflective journal. Students are asked to summarize their learner preference and foreign language learning characteristics and reflect how they better themselves. For example, one student writes 'I'm very interested in my own learner preference and the learning strategies, because knowing my strengths and weaknesses is good for my study. I can find the right way to learn English well. But some professional terms in this unit are hard for me, because they are strange, I think. I can't understand them easily." Another student writes "I think 'Understand Yourself as a Learner' and 'Understanding Learner Preferences' are interesting. Through these parts, I get a clear understanding of myself, and make me a more resourceful English learner. On the one hand, I am happy when I discuss with my friends, on the other hand, I can become more aware of my strengths and weaknesses. It is so useful to improve my learning efficiency. So, I like these parts."

\section{B. Practice of TCLTSP Model in Vocabulary Learning Strategy Training}

Lecture on "Vocabulary learning strategy training" is a typical example of how this strategy training program develops learners' strategies on language skills study.

Time arranged: 135 minutes

Teaching method: team teaching (professor instructing and assistants participating in group discussion, monitoring and observing learners)

Teaching objective: (1) Left-brained or right-brained? Do you understand your brain? (2) What should be known when we are learning new words? (3) Understanding certain strategies on vocabulary learning and retaining.

Warm-up Activities: Students listen to a piece of audio clip and try to note down the important points according to what they are hearing. And then, students do group discussion, comparing notes each group member have put down and reflecting the Question (a) "Why do our notes vary from each other?"

Students get different contents from this piece of audio clip: learners preferring left-ear hearing get the content "One kind of vacation that many of Americans enjoy is camping. Each summer, millions of Americans drive to the countryside where they find places to camp. The National Parks, many of which are in the mountain are favorite camping places. Campers enjoy fresh air, the lakes and the forests which they find in these parks"; learners preferring right-ear hearing get the content "Most Americans business are open five days a week. American school children attend school five days a week as well. American families usually have a two-day weekend. The weekend is Saturday and Sunday. Over the weekend, people spend their time in many different ways. Many families enjoy weekends together." By discussing Question (a), learners can find: some individuals prefer left-ear hearing, some prefer right-ear hearing; some individuals even write down notes from left-ear hearing at one time and notes from right-ear hearing at another time. This task can help learners feel they are left/right-brained preference learner, and they can feel the individual difference in their daily study.

\section{Understanding Yourself as a Learner}

Students discuss in groups Question (b) "Are you more left-brained or right-brained? What might this preference indicate?" Question (b) is an in-depth question of Question (a). After experiencing the difference of left and right brain control, learners need to judge their preference and analyze the advantages of different preference for their language learning. For example, one student argues "I am more left-brained. I don't know what does this mean, but I am always good at mathematics." And another student reflects "I am more of a right-brained type. And I guess that's the reason why I have a special interest in music and art."

After discussing Question (b), teacher shows pictures which demonstrate different functions of left and right brain _"Left Brain: Right-hand Control, Language, Mathematics, Scientific skills, Logical Reasoning, Focus on details; Right Brain: Left-hand Control, Music \&Art Awareness, Imagination, Focus on the general ideas." Teacher explains to 
learners: They may belong to left/right-brained preference learner, and these preferences endow them with different advantages, therefore each learner should try his/ her best to find their strong points; besides, their weaknesses can be compensated by consciously using learning strategies.

To demonstrate learners can compensate their weaknesses brought by the left/right brain preference by using strategies, students are asked to finish the task "Memorize 20 words in 10 minutes." These 20 words are new words for freshmen, and spelling, part of speech, pronunciation, English meaning and Chinese meaning of these words are provided to learners. 10 minutes later, students are asked to do a spelling test and to report how they memorize these words. Learners' reports show that most learners think words which are regularly structured or are easy to pronounce can be easily memorized, and words which are strange and are difficult to separate into morphemes can rarely be memorized. For example, one student mentions his memorizing process "When I memorize the word 'entangle', I recall my senior high school teacher Mr. Tang whose class is always bustle, and I think a phrase 'in Tang's class'.” Another student reports "I like to watch NBA programs; therefore, I think the word 'defensible' is easy to memorize". And another one says "I think the word 'sophisticated' is easy to memorize because I like high technology and I also believe it is hard to be a man of the world." By group discussing, learners can share memorizing methods and enlarge their strategy use zone; besides, they can recognize that although right-brained learners may not be good at language learning, they can compensate it by making full use of "imagination" to help them learn and memorize vocabularies.

\section{Understanding Vocabulary Learning}

Teacher asks students to reflect the "memorizing 20 words" task and discuss another in-depth Question(c) "When you say you have learned a word, what exactly do you know about the word?" In this discussion, assistants teachers need to help students understand: (1) five factors of a word should be covered when we memorizing it - spelling, pronunciation, meaning, collocation, and part of speech; (2) how large is their vocabulary, and a university graduate will have a vocabulary of around 20,000 word families (Goulden, Nation and Read, 1990); (3) one reason why some words are very strange to them and some are familiar is that there are high-frequency words and low-frequency words.

\section{Learning Strategies Use}

Vocabulary learning strategies focus on two questions: Question (d) What methods were used in order to learn and memorize new words? Question (e) What will you do if you meet a new word in your reading or listening activity?

To answer Question (d), assistant teacher helps learners recall methods they use in "memorizing 20 words" task. Learners have various reflections, such as: "I analyzed the words I need to memorize, finding roots and affixes in them"; "I like to read these words again and again, so that I can get deep impression on them"; "I try to read these words and put them down at the same time"; "I like to associate these words with words which I'm familiar with"; "I like to memorize through my imagination and their pronunciations"; "I prefer to use dictionary to help me memorize these words". After discussion, teacher demonstrates some particular methods learners used in this discussion, such as "when I memorize the word 'bewilder', I associate it with "wild" - the word I have learnt long ago"; "I imagine Tango when I memorize the word 'entangle'; "I like to put words in context, so I think of a specific picture of 'exhibition' when I memorize it". Finally, teacher shows and explains "Ebbinhause Curve" to students, and emphasizes the importance of reviewing in vocabulary memorizing.

To answer Question (e), assistant teachers help learners to reflect their daily English learning activity. One group's answers are: when I meet new word, I "look into dictionary; guess its meaning in context; guess its meaning according to its morpheme; underline this new words; ignore it; at least judge its part of speech." This group's answers can illustrate students have different degree of tolerance on new words, which may bring to different learner responses to them.

After discussing Question (d) and (e), teacher instructs two strategies on how to deal with new words - word guessing and consulting a dictionary.

For word guessing, teacher instructs how to guess word meaning based on word formation - affixation (eg., export, import, support, transport, transportation, porter), compounding (eg., record-breaking, chain-smoke), and blending (eg., motel, brunch), and how to guess word meaning based on context clues - definition (eg., The harbor is protected by a jetty ---a wall built out into the water.), example (eg., Cold beverages, like iced tea, fruit juice, coca-cola, and milk shakes are sold everywhere on a hot day.), restatement (eg., He had a wan look. He was so pale and weak that we thought he was ill.), synonym (eg., The new tax law supersedes, or replaces, the law that was in effect last year.), antonym (eg., Unlike her gregarious sister, Jane is a shy, unsociable person who does not like to go to parties or to make new friends.), Inference( eg., My father is a versatile man; he is a successful businessman, sportsman, author, and sports car mechanic.), general knowledge (eg., Mark got on the motorbike, I sat behind him on the pillion, and we roared off into the night.), and logic relation(eg. The State of Texas revoked that driver's license because he had had too many accidents.)

For consulting dictionary, teacher instructs types of dictionary (monolingual, bilingual; general and special, pocket; medium-sized and unabridged; encyclopaedias and encyclopedic; electronic and online), characteristics of e-dictionary and paper-dictionary, and how to choose a proper dictionary.

"Learning Strategies Use" aims to enlarge learner's cognition on vocabulary strategies and improve their strategy repertoire by group discussing, sharing and teacher instruction.

\section{Assignment}


Two tasks are assigned to students in this class. One is group work task -imitate teacher's demo "hair" (see figure 4) and design "word in network". The key word chosen by groups are various, such as "PLA, flower, music, organ, earth, food, etc". Of course, students' problems are found in this task, for example, some students have not participated in the group work; some students are not familiar with the work their groups have done; some students just do the task, but do not memorize words in their groups' network.

Another task is reflective journal. Students are required to write down what they have learnt on vocabulary strategies, and the change of their cognition on vocabulary learning. For example, some reflections are: "I used to remember new words by writing them down while reading aloud, again and again. Now I know that I have to change the way I remember vocabulary. I should make a 'reviewing - regularly plan' to memorize new words, because memorizing has its regular pattern." "I used to view English vocabulary as the most horrible nightmare I had ever had. Now I have realized if I can master some good ways, it would be so easy. I can use vivid image by associating new words with something else that produces memorable image and by visualizing the words. I can connect what I already known to newly acquired vocabulary. Word formation can help me enlarge my vocabulary memory bank. Most importantly, in order to understand one word very well, an English-to-English dictionary is a must."

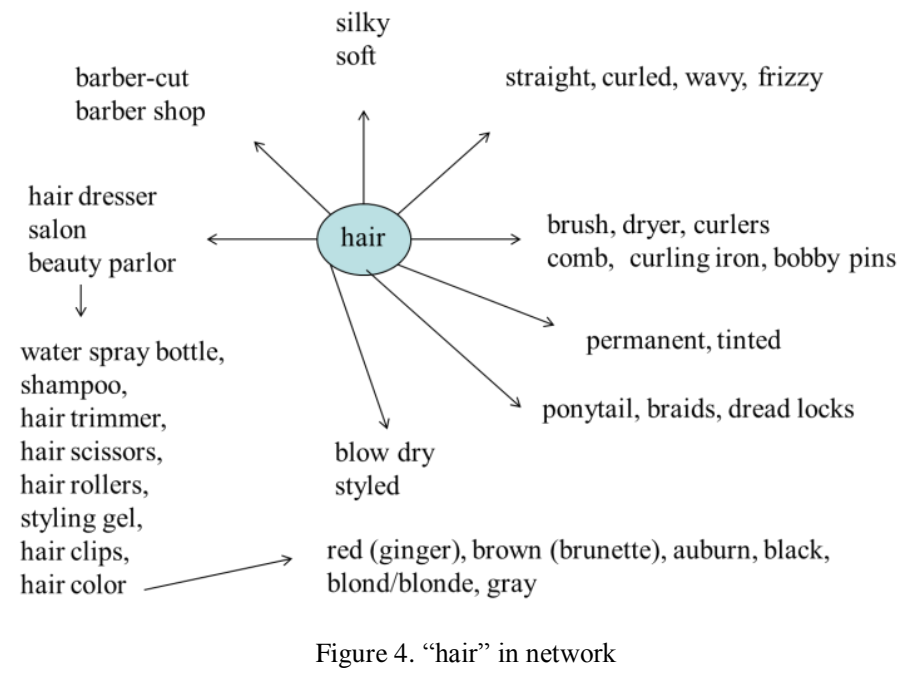

\section{IMPLICATION}

The practice of TCLTSP Model in learner preference and vocabulary strategy training not only demonstrates how teacher train strategies among students, but also displays learners' thinking processes in training class. This practice suggests that compared to simply instructing learning strategies, understanding learner factors and target language in training can help learners better adjust and choose self-adaptive strategies; meanwhile, a lot of tasks are finished in groups in this practice, which encourage learners to share individuals' learning methods and promote their motivation to find their strengths and weaknesses, and eventually choose their adaptive strategies in foreign language learning.

\section{REFERENCES}

[1] Cohen, A. D. (2000). Strategies in Learning and Using a Second Language. Beijing: Foreign Language Teaching and Research Press.

[2] Cohen, A. D. \& S. J. Weaver. (2006). Styles-and Strategies-based Instruction: a Teachers' Guide. Beijing: Foreign Language Teaching and Research Press.

[3] Goulden, R., P. Nation \& J. Read. (1990). How Large Can a Receptive Vocabulary Be?. Applied Linguistics 11, $341-363$.

[4] Kolb, D. A. (1984). Experiential Learning: Experience as the Source of Learning and Development. London: Prentice-Hal.

[5] O’Malley, J.M. \& A. U. Chamot. (1990). Learning Strategies in Second Language Acquisition. Cambridge: Cambridge University Press.

[6] Oxford, R. L. (1990). Language Learning Strategies: What Every Teacher Should Know. Boston: Heinle\& Heinle.

[7] Oxford, R. L. (2001). Language Learning Styles and Strategies. In M. Celce-Murcia (ed.). Teaching English as a Second or Foreign Language. (3rd Edition). Boston: Heinle \& Heinle/ Thompson International, 359-366.

[8] Wenden, A. (1991). Learner Strategies for Learner Autonomy. UK: Prentice Hall.

[9] Zeng, J. (2011). The Course Book of Strategy-based Instructions for Language Learning. Shanghai: Shanghai Foreign Language Education Press.

[10] Zimmerman, B.J. (1990). Self-regulated learning and academic achievement: An overview. Educational Psychologist, 25, 3-17. 
Li Gao was born in Chengdu, China in 1982. She received her bachelor's degree in Literature from Southwest Normal University, China in 2003, and her master's degree in linguistics from Southwest Petroleum University, China in 2010.

She is currently a lecturer in the School of Foreign Languages, Southwest Petroleum University, Chengdu, China. Her research interests include psycholinguistics, second language acquisition and corpus linguistics.

Yun He was born in Zigui County, Hubei Province, China in 1982. She received her bachelor's degree in Literature from Hubei University of Technology in China in 2003, and her master's degree in linguistics from Southwest Petroleum University, China in 2011. She works as a lecturer in the School of Foreign Studies, Yangtze University, Jingzhou, China. Her research is mainly focused on second language acquisition.

Jie Zeng was born in Nanchong, China in 1963. She received her bachelor's degree in Literature from Southwest Normal University, China.

She is currently a professor in the School of Foreign Languages, Southwest Petroleum University, Chengdu, China. Her research interests include psycholinguistics and second language acquisition. 